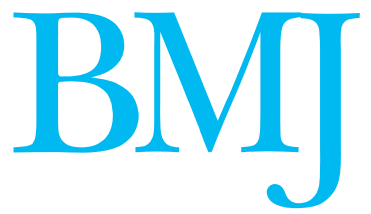

$\Lambda^{\mathrm{t}}$

$\mathrm{t}$ the height of the Arab-Islamic civilisation between the 8th and 12th century, scholars laid the foundation for modern medicine based on observation and reasoning. Avicenna's Al Qanun of Medicine was the standard medical text in Europe for several centuries. In the bimaristans (figure), the mentally ill were treated with water, music, light, and the scent of flowers-testament to enlightened attitudes. Today, the geopolitical remnants of that empire, a legacy of past conflicts and externally imposed boundaries, includes some of the poorest and richest countries in the world, whose basic health indicators generally parallel their economic status.

Many of these countries, rich and poor, spend far more on defence than on health and research and development combined and are lagging behind on major indices of development. ${ }^{23}$ Authoritarian regimes, economic incentives, and conflicts have resulted in the migration of health professionals: an estimated 15000 Arab doctors left their countries between 1998 and 2000. ${ }^{3}$ Wide health disparities within some countries exceed those between rich and poor nations. This issue of the $B M J$ draws attention to these health divides, the high burden of disease associated with preventable conditions, and the lack of political will to tackle them. It also shows how local initiatives can achieve change.

Most countries still lack reliable, regularly updated, population based data on the major causes of morbidity and mortality. ${ }^{4}$ Cardiovascular disease, cancer, and injuries are still not covered by regular surveillance in the Eastern Mediterranean Region. ${ }^{4}$ Where data exist, poor reporting regulations and practices affect their quality and reduce the usefulness of national registries. ${ }^{4}$ Without such data, it is impossible to define health priorities accurately or design effective health systems, let alone assess their impact.

The lack of expertise in systematic collection of data is mirrored by a lack of expertise in its analysis, particularly at governmental level. Academic research, another important component of the study of health, is neither a priority nor a necessity for career advancement in most universities in the region. Arab countries currently produce less than $0.5 \%$ of the papers that are published in the world's top 200 medical journals, ${ }^{1}$ in obvious disproportion to their economic and human capacities. Furthermore, good data are often poorly used because the mechanisms

\section{Health in the Middle East}

\author{
No one's priority, everyone's problem
} (hospitals), still standing in the heart of Aleppo

that connect the production of knowledge (academia) and its consumption (policy makers and the general public) are poorly developed. All these factors contribute to what in most countries is a haphazard distribution of healthcare services.

The failure of governments to provide comprehensive healthcare services has led to health care being taken over by market forces. This has transformed it into a commodity with a curative, rather than preventive, orientation. This shift in orientation means that the development of health systems has been driven by economic opportunities for providers, not the health needs of the population, and this has fueled disparity in access to health care.

Failure of public health systems has also led to the widespread distribution of risk factors for disease, such as smoking, obesity, and hypertension. ${ }^{5}$ Solutions for such health problems cannot necessarily be imported. For example, advocating diet and physical activity to combat the epidemic of obesity among women in Arab societies may be naive. Overwhelmed by having to take care of large households, and deprived of basic knowledge and power to conceptualise life outside traditional frameworks, women may be unable to alter their lives. ${ }^{5}$ Classic socioeconomic disparities in health can overlie more fundamental ones. Greater exploration of power relationships, political representation, gender roles, and normative values of traditional societies is needed to understand and respond to the health needs of local communities. For many people in the region, health improvement must start somewhere else-with education, equality, and security.

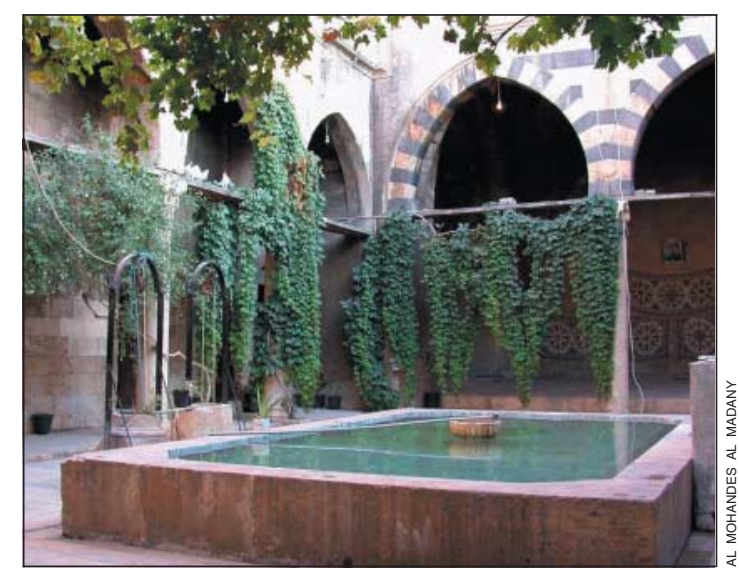

Bimaristan hospital for the mentally ill in Aleppo, Syria 
This level of exploration and understanding requires broad but locally oriented research agendas backed by a vibrant civil society that promotes evidence based health and shields scientific inquiry from dominant social and political doctrines. More research is also needed in "taboo" areas associated with major health problems-for example, domestic violence, mental health, and the health of special groups (such as Palestinian refugees and Kurdish minorities). The taboos may be unwritten but their impact at government level is strong. In authoritarian regimes health ministries have little incentive to present "bad" or politically loaded data or work on such data obtained from other sources, especially as they are not held accountable for failing to do so by independent bodies or a free press.

Against this bleak background, multiple conflicts are tearing the Middle East apart and delaying all aspects of development. These conflicts are used by national governments and outside powers alike to divert public attention from developmental failures. They nourish narrow interests and result in suffering and despair, driving people to regroup along ethnic, religious, and tribal loyalties, which undermine the state's status and erode the community's spirit and trust. Health, along with all facets of life in this turbulent region, can only be improved if nations recognise the importance of investing in science, health, education, and culture. In the long run this is the only way they can provide their populations, rich or poor, with the means to assert their rights and assume responsibility for their own destiny.

Wasim Maziak associate professor of University of Memphis and director of Syrian Center for Tobacco Studies

(wmaziak@memphis.edu)

Syrian Center for Tobacco Studies and University of Memphis, Memphis, TN 38152, USA

Competing interest: None declared.

1 Maziak W. Science in the Arab world: vision of glories beyond. Science 2005;308:1416-8.

2 Islamic Educational, Scientific and Cultural Organisation. Strategy for the development of science and technology in Islamic countries. Rabat, Morocco: ISESCO, 2000. www.isesco.org.ma/Francais/Strat/straSCENG.pdf (accessed 11 Oct 2006).

3 United Nations Development Programme, Arab Fund for Economic and Social Development. Arab human development report 2002. New York: UNDP, 2002.

4 Mathers CD, Fat DM, Inoue M, Rao C, Lopez AD. Counting the dead and what they died from: an assessment of the global status of cause of death data. Bull World Health Organ 2005;83:171-7.

5 Maziak W, Ward K, Mzayek F, Rastam S, Bachir ME, Fouard MF, et al. Mapping the health and environmental situation in informal zones in Aleppo, Syria: report from the Aleppo household survey. Int Arch Occup Environ Health 2005;78:547-58.

doi $10.1136 /$ bmj.39006.478796.80

\title{
Sexual and reproductive health of women
}

\author{
Both informed choice and access to services are needed
}

A ccess to sexual and reproductive health services is central to achieving good maternal and child health but its importance extends beyond this. Sexual and reproductive health engenders a sense of wellbeing and control over one's life, along with an ability to enjoy basic human rights. A broader understanding of sexual and reproductive health was promoted at a development conference-the Cairo International Conference on Population and Development in 1994. ${ }^{1}$ Three articles in this week's BMJ draw together the latest evidence and the challenges ahead for women's health in the Middle East. ${ }^{2-4}$

Elements of sexual and reproductive health are included in three of the eight millennium development goals: reducing child mortality, improving maternal health, and combating HIV and AIDS. Sexual and reproductive health is important in reaching the other goals. ${ }^{5}$

Countries of the World Health Organization Eastern Mediterranean Region (EMRO) have adopted targets set by the millennium development goals; however, the 2005 Millennium Project reports that West Asia is off track for most of them. ${ }^{6}$ This area contains several countries that belong to the EMRO region (Arab Gulf States, Iraq, Jordan, Lebanon, Syria, and Yemen). North Africa, which also includes several countries in the EMRO region (Egypt, Libya, Morocco, and Tunisia) is moving in the right direction, but needs to accelerate progress to achieve the goals.
Improving maternal and newborn health is still a challenge for disadvantaged countries in the region. The proportion of deliveries attended by skilled birth attendants is as low as 22\% in Yemen, 14\% in Afghanistan, and 34\% in Somalia. ${ }^{7}$ In this issue Bhutta and colleagues show that many maternal and child deaths in the region could be prevented by scaling up community based maternal and newborn care services. $^{2}$

The use of contraceptives in married women aged 15-49 varies widely among countries in the EMRO region, from $9.9 \%$ in Sudan to $63 \%$ in Lebanon and Morocco. ${ }^{\mathrm{w} 1}$ For cultural reasons, contraceptive surveys in countries of the region do not include unmarried women.

Key areas of sexual and reproductive health, such as prevention of sexually transmitted infections including HIV, unsafe abortion, and the promotion of sexual health are still largely missing in many countries in the EMRO region. The number of unsafe abortions in the region for the year 2000 is estimated to be 2.6 million and to cause $11 \%$ of all maternal deaths. $^{8}$ An article in this issue by DeJong and El-Khoury shows that young people's reproductive and sexual health needs are largely unmet. ${ }^{3}$ No country from the EMRO region participated in a WHO

\section{References w1-w3 are on bmj.com}

Analysis and Comment pp 839, 849,851 